\title{
Strategi Kualitas Pelayanan Bongkar Muat Peti Kemas Empty Di Depo Armaco Semarang
}

\author{
Agus Pamungkas R.P. ${ }^{a}$, Tini Utami ${ }^{b}$, Victor Wiku WB ${ }^{c}$

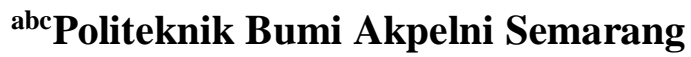 \\ a*Email: aguspamungkas@akpelni.ac.id \\ bEmail: tiniutami@akpelni.ac.id \\ cEmail: tirtasamudera79@gmail.com
}

\begin{abstract}
ABSTRAK
Kegiatan bisnis depo peti kemas kosong pada dasarnya adalah sebagai jasa pelayanan kegiatan menaikkan dan menurunkan (bongkar dan muat) peti kemas kosong sebagai salah satu rangkaian kegiatan ekspor atau impor yang dilakukan oleh eksportir atau importir, khususnya di Jawa Tengah. Tujuan studi ini adalah ingin mengetahui manajemen kegiatan yang dilakukan di suatu depo peti kemas kosong dalam kegiatan operasional bongkar dan muat peti kemas kosong di depo peti kemas. Metode penelitian yang digunakan dalam studi ini adalah metode kualitatif, dengan melakukan survey lapangan, interview dengan pelaku, diskusi, dan telaah literatur-literatur yang berkaitan. Strategi kualitas pelayanan bongkar dan muat peti kemas kosong tidak kalah pentingnya dengan pelayanan operasional lainnya seperti, trucking, ekspedisi muatan kapal laut, forwarding dan lainnya. Kecakapan dan keterampilan sumber daya manusia serta peralatan dalam merawat dan memperbaiki alat bongkar muat peti kemas harus terus dikembangkan.
\end{abstract}

Kata Kunci : Strategi, Kualitas Pelayanan Bongkar dan Muat, Peti kemas, Depo.

\section{PENDAhuluan}

Kegiatan ekspor dan impor yang dilakukan oleh para pengusaha sangat dipengaruhi oleh jasa perusahaan pelayaran, ekspedisi muatan kapal laut, transportasi dan yang tak kalah penting adalah pelayanan jasa depo peti kemas. Perusahaanperusahaan pelayaran dan para pemilik barang tersebut sangat terbantu dengan adanya depo peti kemas, karena depo peti kemas menjadi salah satu komponen penting dalam kegiatan ekspor impor maupun perekonomian nasional. Selain itu persaingan antar usaha depo peti kemas saat ini semakin ketat, hal ini terkait dengan semakin meningkatnya jumlah depo peti kemas di Semarang. Kontradiksi yang terjadi saat ini adalah depo peti kemas yang berdiri memiliki keunggulan komparatif yang menyamai bahkan mulai melampaui depo peti kemas yang sudah ada. Terlebih lagi dengan mulainya para pemilik modal besar yang bekerjasama dengan pengusaha lokal dalam proses pendirian depo peti kemas di Semarang. Depo baru dengan fasilitas dan kualitas yang cukup bagus memiliki akses langsung dengan head office shipping line, maka mereka menjadi pesaing depo peti kemas yang sudah ada. Untuk itu depo peti kemas diperlukan adanya peningkatan pelayanan dan strategi yang lebih baik dalam pelayanan bongkar muat peti kemas kosong dalam melayani para pemilik barang dalam kegiatan ekspor dan impor barang.

Di Jawa Tengah sudah memiliki asosiasi depo peti kemas yang dikenal dengan nama Asosiasi Depot Kontainer Indonesia 
(ASDEKI). Asosiasi ini khususnya membahas mengenai kesetaraan tarif LOLO (lift off lift on) di masing-masing depot yang sudah menjadi anggotanya. Namun untuk saat ini, masih belum ada wadah dalam suatu organisasi/asosiasi depo peti kemas yang membahas mengenai standar pelayanan pada depo peti kemas di Indonesia.

Depo peti kemas merupakan salah satu mata rantai dalam rantai pasok (supply chain) yang sangat penting keberadaannya guna melengkapi rangkaian pasokan dari produsen sampai kepada konsumen berjalan dengan lancar. Menurut PP Gubernur No.119/2011, depo peti kemas adalah suatu area terbuka di dalam atau di luar daerah lingkungan kerja pelabuhan (DLKr) sebagai tempat kegiatan penyimpanan dan penumpukan (storage), pembersihan atau pencucian (washing), perawatan dan perbaikan (maintenance and repair) peti kemas, pemuatan (stuffing), pembongkaran (stripping), serta kegiatan lain yang mendukung kelancaran penanganan peti kemas isi (full container) dan/atau peti kemas kosong (empty container).

Berdasarkan pemaparan di atas, maka penulis ingin mengetahui kegiatan-kegiatan serta strategi kualitas pelayanan bongkar dan muat peti kemas kosong yang dilakukan di depo Armaco.

\section{METODE}

Metode penelitian yang digunakan dalam studi ini adalah metode penelitian kualitatif. Penelitian ini dilakukan dengan melakukan survey lapangan, wawancara dengan pelaku yaitu direktur perusahaan, para manajer dan pekerja. Lalu dilakukan diskusi dengan metode FGD (Focus Group Discussion) dan telaah literatur-literatur yang berkaitan. Obyek penelitian yang ditinjau adalah Depo Peti kemas Armaco, Semarang.
Perusahaan tersebut, memiliki profil sebagai berikut: berdiri sejak tahun 1994, sehingga berpengalaman dalam penanganan peti kemas kosong. Masuk dalam 10 (sepuluh) besar depo peti kemas yang baik dalam hal pelayanan terhadap pelanggan, baik ekspor dan impor. Memiliki strategi kualitas pelayanan bongkar muat serta kualitas yang tinggi dalam hal Maintenance dan Repair Container dari awal Survey in Gate, Pencucian, Perbaikan dan Quality Control-nya berdasar standard IICL (Institute of Internatiional Container Lessors), standar tertinggi dalam perawatan dan perbaikan peti kemas di dunia.

Lokasi usaha Depo Armaco berada dalam Kawasan Workshop Puri Anjasmoro, di Jalan Madukoro Blok E No. 1 Semarang. Keuntungan berada dilokasi yang sangat strategis dan dekat dengan pelabuhan serta instansi pemerintah dan kantor-kantor perusahaan pelayaran dan ekspedisi muatan kapal laut serta pengusaha transportasi darat. Selain itu, keuntungan lainnya adalah dengan lahan yang disewa dari pemilik saham utama, menjadikan efisiensi di biaya sewa kantor di lokasi yang strategis.

Pelabuhan adalah tempat yang terdiri dari daratan dan perairan disekitarnya dengan batas-batas tertentu sebagai tempat kegiatan pemerintah dan kegiatan ekonomi yang dipergunakan sebagai berlabuh, bersandarnya kapal, naik turunnya penumpang dan bongkar muat barang, hewan yang dilengkapi dengan fasilitas keselamatan pelayaran dan kegiatan penunjang pelabuhan serta sebagai tempat perpindahan intra dan antar moda transportasi (UU No.17 tahun 2008).

Pelabuhan termasuk bagian yang penting dari transportasi barang. Pelabuhan merupakan bagian dari infrastruktur dan sistem logistik nasional yang memiliki peranan penting sebagai sarana bongkar dan muat barang untuk diteruskan kepada moda 
transportasi lainnya seperti angkutan truk, kereta api atau dengan tongkang. Operasi dari transportasi ditentukan dari efisiensi dari perpindahan hasil-hasil produksi.

Perkembangan dalam prinsip-prinsip teknik dan manajemen dalam memperbaiki bongkar dan muat, kecepatan pengiriman, kualitas pelayanan, biaya operasi, penggunaan fasilitas dan penghematan energi, transportasi memegang peranan krusial dalam logistik. Bagian proses bisnis yang utama di pelabuhan atau terminal antara lain adalah pengendapan sementara peti kemas terutama untuk barang impor atau disebut dwell time. Dwell time dihitung dari waktu datangnya peti kemas di dermaga dari kapal kemudian diangkut ke lapangan penumpukan menunggu peti kemas tersebut diselesaikan urusan administrasinya dan dilakukan pemeriksaan apabila diperlukan oleh bea dan cukai sampai diambil oleh pemiliknya dan keluar dari pintu gerbang (gate).

Depo peti kemas merupakan sistem yang kompleks dengan interaksi yang sangat dinamis antara berbagai penanganan, transportasi dan penyimpanan unit. Terminal peti kemas adalah tempat pertemuan antara moda transportasi, Peti kemas diangkut oleh kapal, truk atau kereta akan disimpan sementara di lapangan penumpukan untuk kemudian dikirim dengan transportasi yang sama atau berbeda. Di dalam terminal peti kemas diangkat dengan peralatan yang jenisnya berbeda-beda dan di dalam terminal peti kemas dikelompokan menjadi tiga jenis yaitu peti kemas ekspor/outbound, peti kemas impor/inbound dan peti kemas transhipment. (Kim, K.H. \& Gunther, H.O, 2007).

Peran utama terminal/depo peti kemas adalah menurunkan waktu tunggu atau $d$ well time dalam perpindahan peti kemas dari pelabuhan. Karena itu perlu tata kelola yang efisien agar peti kemas cepat bergerak dari pelabuhan kepada pelanggannya. Beberapa penelitian mengenai depo/terminal peti kemas dipaparkan berikut ini. Watanabe (2001) menganalisa pembatas kapasitas, produktifitas dan fleksibilitas dari sistem bongkar muat, peti kemas adalah fungsi dari tipe dan ukuran terminal. Sedangkan Steenken et al. (2004) menyangkut perbedaan aspek operasional dari struktur terminal, termasuk penempatan peralatan bongkar muat dengan mensimulasikan urutan proses operasional untuk memperbaiki kinerja terminal. Kinerja terminal pengaruhi oleh Dwell time, yaitu waktu yang dibutuhkan peti kemas untuk tinggal di terminal setelah dibongkar dari kapal, Dwell time yang berkepanjangan menghasilkan kepadatan peti kemas di lapangan penumpukan dan menimbulkan efek yang substansial merugikan dalam produktifitas terminal dan kapasitas throughput (lalu lintas) peti kemas. Lamanya Dwell time dapat menurunkan produktifitas dari pelabuhan (Holguin, 1998).

Menurut Peraturan Menteri Perhubungan No.PM/83/2016 Tentang Penyelenggaraan dan Pengusahaan Depo Peti Kemas dijelaskan bahwa depo peti kemas adalah suatu tempat di dalam atau di luar Daerah Lingkungan Kerja (DLKr) pelabuhan yang berfungsi untuk kegiatan penyimpanan, penumpukan, pembersihan, pencucian, perawatan, perbaikan peti kemas, pemuatan (stuffing), pembongkaran (stripping), serta kegiatan lain yang mendukung kelancaran penanganan peti kemas isi full dan/ atau peti kemas kosong (empty). Usaha Depo Peti kemas adalah kegiatan usaha yang meliputi penyimpanan, penumpukan, pembersihan, dan perbaikan peti kemas. Kegiatan depo peti kemas dapat dilakukan di dalam atau di luar Daerah Lingkungan Kerja (DLKr) pelabuhan. Kegiatan usaha depo peti kemas dilakukan oleh badan usaha yang terdiri atas: Badan Usaha Milik Negara (BUMN), Badan Usaha Milik Daerah (BUMD), 
Perseroan Terbatas (PT); atau Koperasi yang didirikan khusus untuk usaha depo peti kemas. Kegiatan usaha depo peti kemas wajib memiliki izin usaha dari Gubernur Provinsi pada tempat perusahaan berdomisili. Izin usaha diberikan setelah memenuhi persyaratan administrasi dan teknis.

\section{HASIL DAN PEMBAHASAN}

Usaha jasa depo peti kemas kosong dikelola oleh sebuah perusahaan yang bergerak dalam bidang jasa penitipan peti kemas kosong kegiatan utamanya adalah lift on dan lift off $(\mathrm{Lo} / \mathrm{Lo})$. Peti kemas yang berada di depo bukan merupakan milik dari depo, namun merupakan milik dari shipping line (perusahaan pelayaran yang telah memiliki hubungan bisnis oleh depo agar peti kemasnya dapat disimpan di depo tersebut.

1. Bongkar dan Muat Peti Kemas Kosong (In Gate). Pembongkaran peti kemas kosong dinamakan Lift off empty container, yaitu kegiatan yang di lakukan pada saat peti kemas masuk ke dalam depo baik setelah kegiatan import (consignee) maupun reposition in (shipping line). Dokumen-dokumen yang harus di bawa oleh pihak EMKL (Ekspedisi Muatan Kapal Laut) sebelum masuk ke depo adalah sbb:

a) EIR (Equipment Interchange Receipt) Out dari SP2 dari Port.

b) $\mathrm{DO}$ (Delivery Order) yang menyatakan bahwa peti kemas tersebut dikembalikan ke depo yang ditunjuk oleh Perusahaan Pelayaran terkait.

c) DO yang dibawa masih dalam masa validasi penerimaan. Apabila DO yang di bawa telah mati/expired, maka pihak EMKL harus mengurus terlebih dahulu kepada pihak shipping line.
Kegiatan pembongkaran peti kemas ini dilakukan oleh petugas atau driver alat handling yang berpengalaman dengan dipandu oleh petugas Stowage Plan dan peti kemas ditempatkan pada lokasi yang sudah ditetapkan dan sesuai dengan prosedur penumpukan peti kemas dan mempermudah proses selanjutnya.

Selanjutnya kegiatan pemuatan peti kemas (Lift On) yang dilakukan oleh depo peti kemas dalam melayani pemilik barang untuk ekspor, adapun Dokumen-dokumen yang harus di bawa oleh pihak EMKL saat akan mengambil peti kemas untuk kegiatan ekspor adalah sebagai berikut:

a) Delivery Order (DO) yang telah dikeluarkan oleh shipping line. Depo wajib melakukan validasi DO melalui sistem maupun e-mail yang dikirim oleh shipping line.

b) Selanjutnya pengecekan Kartu Tanda Penduduk dari petugas Ekspedisi Muatan Kapal Laut (EMKL) yang akan mengambil peti kemas tersebut.

c) Melengkapi data-data yang diperlukan dalam proses input data di sistem dalam kegiatan stuffing peti kemas yang akan dilakukan oleh shipper.

d) Kegiatan selanjutnya diantaranya pemilihan peti kemas sesuai DO dan dilakukan pengecekan sebelum peti kemas dikirim ke gudang shipper.

e) Penerbitan EIR Out (Equipment Interchange Receipt Out) atau Surat pengeluaran peti kemas keluar depo dan ditandatangani oleh kedua belah pihak, bahwa peti kemas telah diterima dan sesuai dengan DO yang ada dengan kondisi bersih dan laik muat.

f) Pihak Depo segera mengirimkan dokumen tersebut ke perusahaan pelayaran sebagai laporan bahwa DO yang dikeluarkan telah dilaksanakan dan telah diterima oleh EMKL sebagai wakil dari pemilik barang. 
Kegiatan pemuatan peti kemas ini dilakukan oleh petugas atau driver alat handling yang berpengalaman dengan dipandu oleh petugas Stowage Plan dan peti kemas dapat diambilkan dari lokasi yang sudah ditetapkan dan sesuai dengan prosedur pengambilan $(F i / F o)$ First In Fisrt Out atau peti kemas masuk dahulu wajib keluar dahulu agar mempermudah proses dan sesuai keinginan dari pemilik barang serta kegiatan dapat berjalan dengan lancar, cepat, tepat dan aman.

\section{Proses Survey In Container}

Pelaksanaan saat proses peti kemas masuk depo harus disiapkan oleh pihak depo, khususnya petugas Surveyor. Seorang Surveyor (petugas pemeriksa kondisi peti kemas) harus orang yang teliti dan kredibel, yakni harus dapat melakukan pengecekan peti kemas dengan teliti dan berbekal ketrampilan dan pengetahuan yang cukup tentang peti kemas dan cara penanganan perbaikannya jika ditemukan kerusakan saat kegiatan pengecekan peti kemas. Pengecekan peti kemas tersebut dilakukan saat peti kemas masih berada di atas truck, sehingga meminimalisasi hal-hal yang terkait dengan Claim (tuntutan ganti rugi) yang muncul. Adapun skill yang dikehendaki adalah memahami dan mengerti tentang prosedur pencucian, prosedur survey, kriteria container, container repair berdasar standard IICL (Institute of Internatiional Container Lessors). Surveyor juga harus memahami komponen-komponen container beserta code ISO CEDEX (Container Equipment Data Exchange ).

3. Proses Input Data

Setelah disurvey, pengemudi truk akan menuju loket kasir membawa dokumen dan kertas hasil survey, untuk membayar biaya Lift Off. Petugas Kasir akan cek ulang kelengkapan dokumen, validasi pengembalian peti kemas, dan dokumen lainnya. Setelah membayar akan diberikan kuitansi dan kartu untuk bongkar peti kemas. Jika peti kemas kondisi "available" diberikan kartu bongkar berwarna putih, sedangkan jika peti kemas "rusak/damage", diberikan kartu bongkar berwarna merah. Hal ini bertujuan untuk memudahkan petugas lapangan dalam mengarahkan dan menyusun peti kemas. Petugas equipment control akan menginput data container berdasarkan dokumen yang dibawa oleh sopir truk dan hasil dari surveyor tersebut ke sistem depo yang selanjutnya dilaporkan ke perusahaan pelayaran masing-masing sesuai data dan DO yang diterbitkan oleh masingmasing perusahaan pelayaran.

\section{SIMPULAN}

Depo peti kemas kosong merupakan sebuah perusahaan yang bergerak dibidang jasa penitipan peti kemas kosong yang di mana kegiatannya adalah lift on dan lift off empty container (muat dan bongkar peti kemas kosong). Untuk itu diperlukan alatalat handling yang sesuai peraturan menteri perhubungan yang berlaku dan dibutuhkan tenaga kerja atau Sumber Daya Manusia (SDM) yang ahli dalam menjalankan peralatan tersebut karena menggunakan sistem dan strategi yang dikembangkan berbasis sistem, sehingga kegiatan dapat berlangsung dengan cepat, tepat dan aman. Peti kemas yang berada di depo bukan merupakan milik dari depo namun, merupakan milik dari shipping line yang telah memiliki perjanjian bisnis oleh depo agar peti kemasnya dapat di kembalikan di depo tersebut. Dalam membangun sebuah depo peti kemas harus berlandaskan kepada Peraturan Menteri Perhubungan no 83 tahun 2016. Selain itu diperlukan sistem serta 
ISSN : 2087-3050

strategi dengan kualitas pelayanan bongkar muat peti kemas yang dapat diandalkan.

\section{DAFTAR PUSTAKA}

Kim, K.H. \& Gunther, H.O. (2007). Container terminals and cargo sistems : design, operations management, and logistics control issues. Berlin (DE): Springer-Verlag Berlin.

Peraturan Gubernur nomor 119 tahun 2011 tentang penyelenggaraan dan pengusahaan depo- peti-kemas.

Peraturan Menteri Perhubungan nomor 83 tahun 2016.

Watanabe, I. (2001). Container terminal planning - a theoretical approach. World Cargo News Publishing, Leatherhead, UK.

http://www.dephub.go.id/ Diakses pada tanggal 11 Juli 2020, 19.23.

http://www.iicl.org/ Diakses pada tanggal 11 Juli 2020, 20.12. 